\title{
Tardive Dyskinesia Associated with Bupropion
}

\author{
Taha Can Tuman ${ }^{1}$, Uğur Çakır ${ }^{1}$, Osman Yıldırım ${ }^{1}$, Mehmet Akif Camkurt ${ }^{2}$ \\ ${ }^{1}$ Izzet Baysal Teaching and Research Hospital for Psychiatry, Bolu, ${ }^{2}$ Department of Psychiatry, Afşin State Hospital, K. Maraş, Turkey
}

\begin{abstract}
Present report describes a 46 year old male patient with a diagnosis of major depression who developed tardive dyskinesia during bupropion therapy. Our patient had no history of neuroleptic use and his laboratory and neurologic examinations were normal. He had no family history of neurologic diseases. Although bupropion induced dyskinesia has been previously reported in the literature, it is rare and our case is the first case regarding tardive dyskinesia.
\end{abstract}

KEY WORDS: Movement disorders; Bupropion; Depression.

\section{INTRODUCTION}

Bupropion extended-release (XL) is an important pharmacological option except nicotine for the treatment of smoking cessation. It is thought to act on nicotine addiction by blocking dopamine reward pathway and reducing withdrawal symptoms that arise due to noradrenaline pathway Furthermore, bupropion is used for the treatment of major depression because of it acts as noradrenaline dopamine reuptake inhibitor. ${ }^{1-3)}$ The most common side effects with the use of bupropion can be listed as insomnia, headache, dry mouth, rash, nausea, sweating and hypertension. ${ }^{4)}$ Hypomania, psychotic relapse and visual hallusinations may also occur via use of bupropion. ${ }^{5,6}$

According to the Diagnostic and Statistical Manual of Mental Disorders, Fifth Edition (DSM-5), tardive dyskinesia is characterized by choreiform or atetoid involuntary movements at least continuing several weeks due to neuroleptic use at least several months. These involuntary movements are often seen on face, arms, legs, jaws and tongues. ${ }^{7)}$ Additionally, tardive dyskinesia may develop with drugs except neuroleptics. ${ }^{8}$ Here, we report an adult patient who developed tardive dyskinesia during

\footnotetext{
Received: May 13, 2016 / Revised: June 4, 2016

Accepted: June 10, 2016

Address for correspondence: Taha Can Tuman, MD Izzet Baysal Teaching and Research Hospital for Psychiatry, Bolu, Turkey

Tel: +90-5342200749, Fax: +90-3742752423

E-mail: tahacantuman@hotmail.com

*Part of the case was reported as a poster at the 50th National Psychiatry Congress (12.11.-16.11.2014, Rixos Sungate Hotel, Antalya, Turkey)
}

treatment with bupropion. Informed consent was obtained from the patient.

\section{CASE}

Forty-six year old man was admitted to our psychiatry outpatient unit with complaints of malaise, unwillingness, fatigue, lack of energy, lack of sexual desire, hypersomnia. His physical and laboratory examination (complete blood count, thyroid function, B12 and folate tests) were normal. The patient received 15 points in the Hamilton Rating Scale for Depression (HAM-D) scale. Bupropion XL 150 mg per day treatment was started to the patient with a diagnosis of major depression according to the DSM-5. After a month, due to continued complaints of depression, bupropion XL dose was increased to $300 \mathrm{mg}$ per day. After two months of dose increase, the patient was admitted to our outpatient unit with complaints of involuntary movements on his tongue and lips. We noted the patient to have repetative buccolingual dyskinesia. Involuntary movements was more pronounced when patient became anxious. His neurologic and laboratory examination were normal. He had never been exposed neuroleptic medication in patients' history. There was no familly history of neurological disorders. Any pathology was not detected with cranial magnetic resonance imaging. The patient received 7 points in the Abnormal Involuntary Movement Scale (AIMS). Bupropion XL dose was decreased to 150 mg per day. After a month, due to continued involuntary movements, bupropion was stopped. Lorazepam $1 \mathrm{mg}$ per day was started for his tardive dyskinesia symtoms.

(c) This is an Open-Access article distributed under the terms of the Creative Commons Attribution Non-Commercial License (http://creativecommons.org/licenses/by-nc/4.0) which permits unrestricted non-commercial use, distribution, and reproduction in any medium, provided the original work is properly cited. 
Involuntary movements disappeared five months after discontinuation of bupropion. Naranjo Adverse Drug Reaction Probability Scale was evaluated as 7 points, a probable adverse effect associated with bupropion. ${ }^{9}$

\section{DISCUSSION}

To our knowledge, this is the first case report regarding tardive dyskinesia associated with bupropion XL in a patient with no history of neuroleptic use or neurologic disorders. Anormal involuntary movements apperared two months after bupropion dose was increased to $300 \mathrm{mg}$ per day and disappeared five months after discontinuation of bupropion with simultaneous use of lorazepam. In literature, there has been three reported cases of dyskinesia associated with bupropion. In first case, 70 year old woman with bipolar disorder, dyskinesia developed 2 days after bupropion IR $75 \mathrm{mg}$ per day was added to her lithium treatment. $^{10)}$ In second case, 63 year old man with major depression, dyskinesia developed one week after bupropion XL dose was increased to $300 \mathrm{mg}$ per day and this patient had a history of neuroleptic medication. ${ }^{11)}$ In third case, 64 year old woman with major depression, dyskinesia developed one week after bupropion dose was increased to $300 \mathrm{mg}$ per day. ${ }^{12)}$ In all three cases, dyskinesia developed acutely. Patients were elderly in previous three cases therefore early stages of Parkinson disease or other neurologic disorders has been associated with dyskinesias after initiation of bupropion. According to DSM-5, dyskinesia associated with bupropion in our patient noted as tardive because of involuntary movements occured two months after bupropion dose was increased to $300 \mathrm{mg}$ per day and disappeared five months after discontinuation of bupropion. Also, our patient was 46 years old so he was quite young for onset of neurologic diseases compared with other cases in literature and there was no history of neuroleptic use in our patient.

Involuntary movements may occur with short term use of drugs as bromocriptine and L-Dopa or lasting than a few weeks in which case the condition is called acute dyskinesia, if these movements develop with use of drugs for at least a few months and lasting a few weeks is called tardive dyskinesia according to DSM-5. ${ }^{7,13)}$ In some patients acute dyskinesia may develop after reduction or discontinuation in dosage of drugs which is called withdrawal dyskinesia lasting less than 4-8 weeks. If dyskinesia persists for longer than this time is called tardive dyskinesia. ${ }^{7)}$ Yet, there is no effective and safety treatment and main treatment strategy is preventive approaches for tardive dyskinesia and it causes permanent disability, therefore tardive dyskinesia is important to early diagnosis of tardive dyskinesia in clinical practice. ${ }^{14,15)}$

Neuroleptic induced tardive dyskinesia develops via dopamin receptor hypersensitivity, reduction in GABA cycle and increased glutamate and aspartate levels after D2 receptor blokage. ${ }^{16)}$ The mechanism of tardive dyskinesia associated with bupropion is still unclear. Excessive dopaminergic transmission in striatum caused by bupropion could be the underlying mechanism of bupropion associated tardive dyskinesia. ${ }^{13)}$ Other prodopaminergic agents such as modafinil, methylphenidate, levodopa, amphetamine and other stimulants have been reported to be associated with involuntary movements. ${ }^{13,17-19)}$

Finally, clinicians should be careful about tardive dyskinesia associated bupropion when they used this drug even if the patient is not elderly. Our findings must be supported by further studies. New studies may contribute to understand the mechanism of bupropion associated tardive dyskinesia.

\section{REFERENCES}

1. Benowitz NL. Pharmacology of nicotine: addiction, smokinginduced disease, and therapeutics. Annu Rev Pharmacol Toxicol 2009;49:57-71.

2. Richmond R, Zwar N. Review of bupropion for smoking cessation. Drug Alcohol Rev 2003;22:203-220.

3. Glynn DA, Cryan JF, Kent P, Flynn RA, Kennedy MP. Update on smoking cessation therapies. Adv Ther 2009;26: 369-382.

4. Dwoskin LP, Rauhut AS, King-Pospisil KA, Bardo MT. Review of the pharmacology and clinical profile of bupropion, an antidepressant and tobacco use cessation agent. CNS Drug Rev 2006;12:178-207.

5. Aggarwal A, Sharma RC. Bupropion-induced mania and hypomania: a report of two cases. J Neuropsychiatry Clin Neurosci 2011;23:E51-E52.

6. Golden RN, James SP, Sherer MA, Rudorfer MV, Sack DA, Potter WZ. Psychoses associated with bupropion treatment. Am J Psychiatry 1985;142:1459-1462.

7. American Psychiatric Association. Desk reference to the diagnostic criteria from DSM-5. Arlington, VA:American Psychiatric Association Publishing;2013.

8. Kenney C, Hunter C, Davidson A, Jankovic J. Metoclopramide, an increasingly recognized cause of tardive dyskinesia. J Clin Pharmacol 2008;48:379-384.

9. Naranjo CA, Busto U, Sellers EM, Sandor P, Ruiz I, Roberts EA, et al. A method for estimating the probability of adverse drug reactions. Clin Pharmacol Ther 1981;30:239-245.

10. Gardos G. Reversible dyskinesia during bupropion therapy. J Clin Psychiatry 1997;58:218.

11. Kohen I, Sarcevic A. Mirtazapine in bupropion-induced dyskinesias: a case report. Mov Disord 2006;21:584-585.

12. Ferentinos P, Christodoulou C, Rizos E, Douzenis A, Lykouras L. Mixed-type (limb-truncal and orofacial) bupropion-associated dyskinesia. J Clin Psychopharmacol 2010; 30:644-646. 
13. Damier P. Drug-induced dyskinesias. Curr Opin Neurol 2009;22:394-399.

14. Kang NR, Kim MD. Tardive dyskinesia: treatment with aripiprazole. Clin Psychopharmacol Neurosci 2011;9:1-8.

15. Egan MF, Apud J, Wyatt RJ. Treatment of tardive dyskinesia. Schizophr Bull 1997;23:583-609.

16. Sachdev PS. The current status of tardive dyskinesia. Aust N Z J Psychiatry 2000;34:355-369.

17. Heinrich TW. A case report of methylphenidate-induced dyskinesia. Prim Care Companion J Clin Psychiatry 2002; 4:158-159.

18. Luborzewski A, Regen F, Schindler F, Anghelescu I. Modafinil-induced reversible hyperkinetic nondystonic movement disorder in a patient with major depressive disorder. $J$ Neuropsychiatry Clin Neurosci 2006; 18:248-249.

19. Jiménez-Jiménez FJ, García-Ruiz PJ, Molina JA. Druginduced movement disorders. Drug Saf 1997;16:180-204. 